doi.org/10.46291/ISPECIJSSHvol4iss2pp59-76

\title{
Borsa İstanbul Teknoloji Endeksi (XUTEK) Şirketlerinin Altman Z-Skor Analizi İle Değerlendirilmesi
}

\section{Sinan Gülençer}

\author{
Eskişehir Osmangazi Üniversitesi, Meşelik Kampüsü, Sağlık Hizmetleri Meslek Yüksek \\ Okulu, E-posta: sinang@ogu.edu.tr
}

Adalet Hazar

\begin{abstract}
Başkent Üniversitesi, Ticari Bilimler Fakültesi, Bankacılık ve Finans Bölümü, Ankara, Türkiye, E-posta: ahazar@baskent.edu.tr
\end{abstract}

\section{Özet}

Çalışmanın amacı Borsa İstanbul XUTEK endeksinde işlem gören teknoloji firmalarının Altman Z-Skor ile finansal başarısızlık ve iflas riskini analiz etmektir. Teknoloji firmaları başlangıç yatırımları ve AR-GE süreçleri açısından yoğun risk taşımaktadır. Teknoloji firmalarının içerisinde bulundukları sektör, çok hızlı dönüşümlerin meydana geldiği ve hızlı aksiyonlar alınması gereken aktif bir sektör konumundadır. Çalışma BISST XUTEK endeksi içinde işlem görmekte olan 16 teknoloji şirketi üzerinde gerçekleştirilmiştir. Altman Z-Skor ile gelecekteki finansal başarısızlık ve iflas riskini ölçümleme amacıyla 16 teknoloji şirketine ait 2019 bilanço verileri kullanılarak elde edilen sonuçlar değerlendirilmiştir. İmalat dışı ve hizmet sektörleri için geliştirilen Altman Z-Skoru modeli kullanılmış, BİST 2019 hisse değer değişimlerine de bakılmıştır. Çalışma konusu şirketler arasında sadece İndes firması gri bölgede kalmış, diğer hisselerin Z-skor puanı 2,6'nin üzerinde olup, finansal başarılı olarak belirlenmiştir.

Anahtar Kelimeler: XUTEK, Performans Analizi, Finansal Analiz, Altman Z-Skor, Teknoloji Şirketleri

\section{Evaluation of Borsa Istanbul Technology Index (XUTEK) Companies by Altman Z-Score Analysis}

\section{Abstract}

The aim of the study is to analyze the financial failure and bankruptcy risk of technology companies traded in Borsa Istanbul XUTEK index with Altman Z-Score. Technology firms carry intense risks in terms of initial investments and R\&D processes. The sector in which technology companies are located is an active sector where rapid transformations occur and fast actions are required. The study was carried out on 16 technology companies traded within the BIST XUTEK index. With Altman Z-Skor, the results obtained by using the 2019 balance sheet data of 16 technology companies were evaluated to measure the risk of future financial failure and bankruptcy. Altman Z-Score model developed for non-manufacturing and service sectors was used, and BIST 2019 share value changes were also examined. Among the companies subject to the study, only Indes company remained in the gray region, while the $\mathrm{Z}$-score score of other shares was determined as 2.6 financial successes.

Keywords: XUTEK, Performance Analysis, Financial Analysis, Altman Z-Score, Technology Companies Year 4/ 2020, Volume-4, Issue-2 | wWw.ispecjournal.org 


\section{Giriş}

Teknoloji sektörü, hızlı gelişim ve dönüşümleri sağladığg için tüm ülkelerde stratejik öneme sahip sektörler arasında yer almaktadır. Ülkeler arasındaki sınırların kalkıyor olması ve insanların ortak alışkanlıklar oluşturuyor olması yeni bir küreselleşme çağının hızlı bir şekilde oluştuğunu göstermektedir. Geçişken sınırların oluşması ülkeler arasında en hızlı akışın bilim ve teknoloji alanında olduğunu göstermektedir. Teknoloji iş yapış şekillerini hızla değiştirmekte, maliyetleri azaltmasının yanında her sektör için katkı sağlayarak daha etkin, verimli çalışılmasını sağlamaktadır. İleri teknoloji ürünlerini üretebilmek AR-GE ve Start-up oluşumlarının desteklenmesi, ülkeler ve şirketler açısından rekabet gücünü korumak ve sürdürülebilir inovatif süreçleri gerçekleştirebilmek için hayati önemdedir. Ülkeler rekabet gücünü koruyabilmek ve küresel ekonomi içerisinden daha yüksek pay alabilmek için, yüksek teknoloji ürünleri üretmeye ve üretim süreçlerine entegre etmeye başlamışlardır (Toker ve Çınar, 2018, s. 139).

Teknolojik gelişim ülke ekonomisi içerisinde yer alan tüm sektörleri doğrudan ve dolaylı yollardan etkilemektedir. Doğrudan etkinin yansımaları, sektörlerin şu an emek yoğun işlerden telekomünikasyon, yazılım ve donanım yatırımlar ile daha etkin, verimli iş süreçleri oluşturma yönündeki çalışmaları ile ilişkilendirilebilir. Dolaylı etki ise teknolojilerin iş süreçlerine entegrasyonu sonucu iş süreçlerini tamamen değiştiriyor olması ve her sektörün yeni etkin yapılar oluşturarak daha hızlı ve etkin çalışmaya başlaması, müşteriler ve şirketler açısından avantaj sağlayan dönüşümler anlamına gelmektedir (Fındık ve Tiryakioğlu, 2017, s. 640).

Türkiye Bilişim Sanayicileri Derneği (TUBİSAD) Nisan 2018 yılında Pazar Verileri raporunu yayınlamıştır. $\mathrm{Bu}$ raporda TUBİSAD, Deloitte ile birlikte Bilgi ve İletişim Teknolojileri Pazarının kapsam ve metodolojisini aşağıdaki şekilde yer aldığı haliyle tanımlamıştır (www.tubisad.org.tr). 


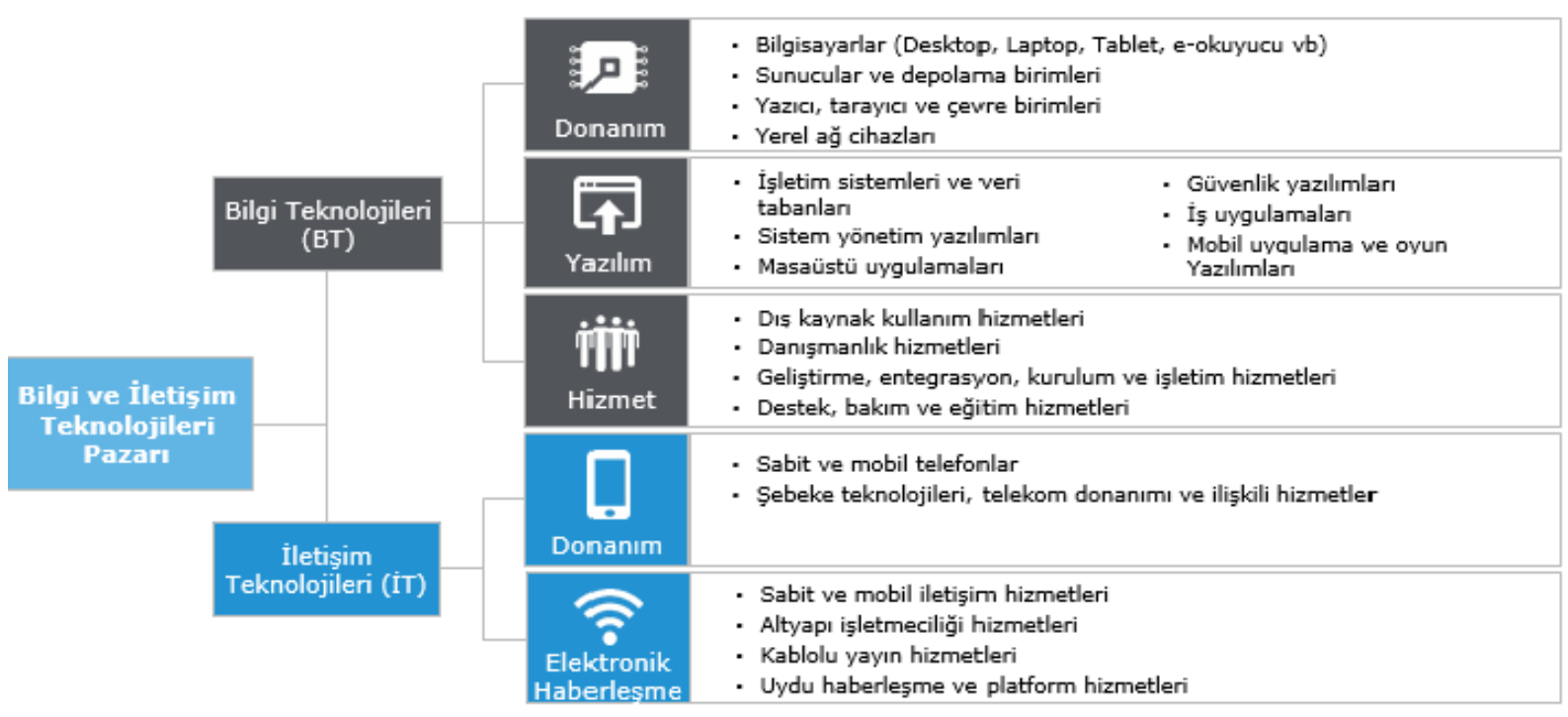

Grafik 1: Bilgi ve İletişi Teknolojileri Pazar Dağılımı, Kaynak: www.tubisad.org.tr

TUBİSAD Nisan 2018 raporunda aynı zamanda sektör şirket sayılarının 2012 yılında 952' den 2018 yılında 5.405' e ulaştığını, bu çerçevede sayıların kısa sürede hızlı artışına dikkat çekmiştir.

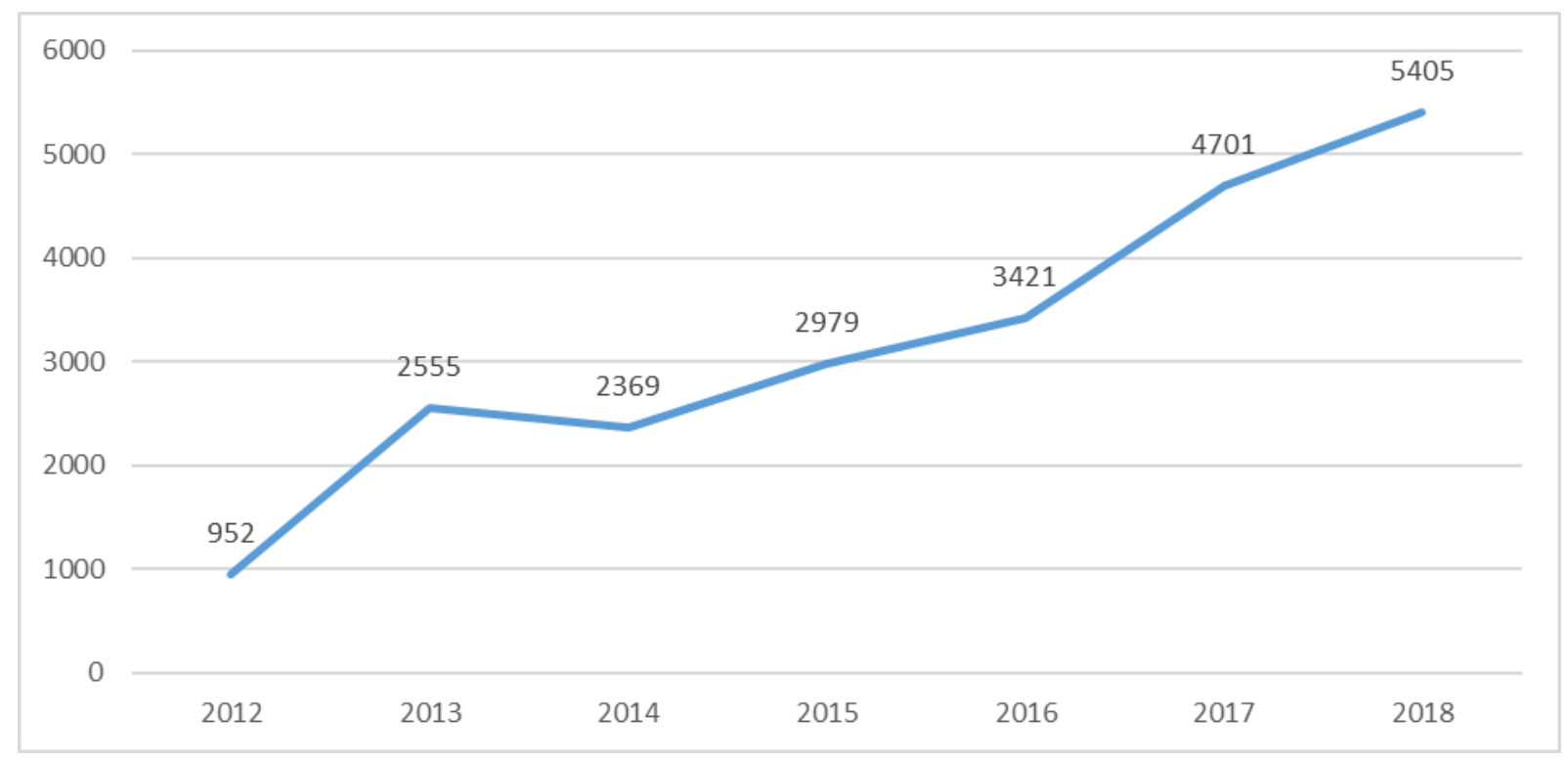

Grafik 2: Bilgi ve İletişim Teknolojileri Alanında Firma Sayıları, Kaynak: www.tubisad.org.tr

Sektör şirket sayılarının artışı aynı zamanda Türkiye Bilgi ve İletişim Teknolojileri pazarının 2018 yılında \%15 büyüyerek 131,7 milyar TL ulaşmasını sağlamıştır (www.Tubisad.org.tr). 
Teknoloji şirketleri bir taraftan doğrudan katma değer sağlarken, diğer taraftan da farklı sektörlerin üretim ve hizmet süreçlerini destekleyerek zincirleme bir fayda dalgası oluşturmaktadır. Ayrıca yüksek teknoloji ürün ve hizmetleri Türkiye gibi cari açığı yüksek ülkeler için tartışmasız stratejik bir konumdadır.

Çalışmanın amacı stratejik konumu, rekabet gücüne etkisi ve diğer sektörlerin de gelişimini destekleyerek hızlandırması nedeniyle önemli bir konuma sahip halka açık işlem gören teknoloji şirketlerinin performanslarının incelenmesidir. Teknoloji şirketlerinin finansal performanslarında; başlangıç yatırımları, AR-GE süreçleri, uzmanlaşma ve hızlı dönüşüm kriterleri önemli yere sahiptir. Bu çerçevede teknoloji firmaları stratejik olduğu kadar riskli bir sektör konumundadır.

Mevcut çalışma Borsa İstanbul XUTEK endeksi içinde işlem görmeye devam eden teknoloji şirketlerinin finansal başarısızlık ve iflas riski çalışmasını Altman Z-skor yöntemi ile gerçekleştirmektedir. Finansal başarısızlık; mali sıkıntılar ile baş edemeyen şirketlerin iflas noktasına gelmeleri ve mali ihtiyaç ve yükümlülüklerini karşılayamama durumlarıdır. Finansal başarısızlık yükümlülüklerini yerine getirememe nedeniyle oluşan mali yetersizlik sonucu konkordato ilanı ile iflas istemi yaparak son bulan bir süreci meydana getirir (Çelik, 2018, s.526). Finansal başarısızlık durumu için aşağıdaki 4 unsurdan söz etmek gerekir (Altman ve Hotchkiss, 2006; Aktaran Özdemir vd, 2012, s.23):

- Söz konusu işletmenin faaliyetlerine devam edememesi ya da iflası,

- İşletme varlıkları üzerine haciz, rehin ve icra gibi durumların meydana gelmesi,

- İşletmenin faaliyetlerini tasfiye etmesi, kayyum ataması olması ya da yeniden yapılandırma gibi kanuni süreçlerin başlaması,

- İşletmenin yükümlülükleri için karşı taraf ile uzlaşma yolunu tercih etmesi.

Finansal başarısızlık ile ilgili ilk çalışmalar arasında yer alan Braver (1966)'ın çalışmasında, iflas riskinin önceden tahmin edilmesinde çeşitli muhasebe rasyoları kullanılmıştır. Altman-Z skoru finansal başarısızlık ve iflas riski için 1968' den günümüze kadar geçen zamanda en çok kullanılan yöntemlerin başında gelmektedir. Altman (1968) yılında firmaların iflas durumlarını önceden tahmin edebilmek için finansal oranlar ve diskriminant yöntemi ile model oluşturmaya çalışmıştır. Altman Z-Skor modeli şirketlerin yaklaşan iflas riskini belirlemede kullanılan en iyi modeller arasında yer alır (Hayes ve diğerleri, 2010, s. 122). Teknoloji şirketleri hassas bir sektörde bulunmaları nedeniyle finansal risklere daha açık Year 4/ 2020, Volume-4, Issue-2 | wWw.ispecjournal.org 
olduğu kadar, yatırımcılar açısından da yüksek riskli görülebilmektedir. Rekabetin hızlı ve güçlü yaşandığı teknoloji sektöründe bulunan şirketlerin finansal temelleri ve risk uyarı sistemlerinin güçlü pozisyonda bulundurmalarını gerektirmektedir.

\section{Literatür}

Aksoy ve Göker (2018) Borsa İstanbul' da işlem görmekte olan ticari bankaların 2012-2016 yılları arasında risk düzeylerini Altman Z-Skor ve Bankometer modeli ile ölçümlenmeye çalışmıştır. Çalışmaya konu 10 ticari bankanın borç ödeme düzeyi yüksek çıkarken Altman ZSkor sonuçları ise tam tersi ölçüde çıkmaktadır. İki yöntem arasında zıt sonuçlara ulaşılmıştır.

Orçun ve Eren (2017) Borsa İstanbul'da XUTEK endeksi içerisinde işlem görmekte olan teknoloji firmalarının finansal performanslarının analizini TOPSIS yöntemi ile gerçekleştirilmiştir. Analiz sonucu ASELS, LINK, ARMDA, LINK, İNDES ve DGATE şirketleri diğerlerine göre daha yüksek performans sergilemişlerdir.

Toker ve Çınar (2018) Türkiye' de ihracatın ithalatı karşılama oranları arasındaki ilişkiyi Borsa İstanbul teknoloji endeksi (XUTEK) firmaları üzerinde incelemeye çalışmıştır. Çalışma XUTEK şirketlerinin Mart 2016- Şubat 2018 tarihleri arasındaki ithalat ihracat verileri üzerinde gerçekleştirilmiştir. XUTEK endeksinde işlem gören şirketlerin ihracatın ithalatı karşılama oranı ilişkisinin pozitif yönlü olduğunu ortaya çıkmıştır.

Kulalı (2016) 2000-2013 yılları arasında Borsa İstanbul'da işlem gören iflas etmiş şirketler için karşılaştırma çalışması yapmıştır. Yapılan finansal başarısızlık analizinde Altman ZSkoru yöntemi kullanılmıştır. Yöntem 19 şirket için kullanılmış ve iflastan bir yıll önce \%95 ve iki yıl önce $\% 90$ oranında tahmin yüzdelerine ulaşılmıştır.

Sulub (2014) uluslararası 10 şirket üzerine 2014 yılından başlayarak 2 yıl boyunca finansal başarısızlık analizi için Altman Z-Skor yöntemi kullanmıştır. Analiz 5'i iflas etmiş 5'i ise faaliyetlerini sürdürmeye devam eden 10 uluslararası şirket üzerinde gerçekleştirilmiştir. Altman Z-skoru ile ulaşılan sonuçlara göre; bu yöntemin başarısız şirketler üzerinde \%70 tahmin gücü olduğu, işlemeye devam eden şirketler üzerinde \%55 tahmin gücü sonucuna ulaşılmıştır.

Mammadli ve Helhel (2017) 2013-2016 y1lları arasında "Fortune: 100 Best Companies to Work for" listesinde yer alan 3 şirketin finansal başarısızlık olasılığını Altman Z-skor yöntemi kullanarak hesaplamıştır. Çalışmada verileri kullanılan 3 şirket arasından The Cheesecake 
Factory restoranı diğer şirketler olan Hyatt ve Marriott International otellerine göre daha iyi sonuçlara ulaşmıştır.

Nadirli (2015) bankaların kredi riskine ilişkin Altman Z-skor yöntemi ile ulaşılan sonuçların zamanında ve doğru değerlendirilmesi halinde fayda sağlayacağına ilişkin vurgu yapmıştır.

Özdemir (2014) halka açık ve halka açık olmayan şirketlerin incelenmesinde tek düzen muhasebe sistemi (TDMS) yanında Altman Z, Z' ve Z' ( $Z$ =halka açık imalat sektörü Z'= halka açık olmayan imalat sektörü Z"=imalat dışı, hizmet sektörü )Skor modellerinin Türkiye için uygulanmasının değerlendirmesini gerçekleştirmiştir. TDSM dayalı finansal verilere dayalı olarak elde edilen analiz sonuçları finansal başarısızlık ölçümü için halka açık olmayan işletmeler ve halka açık işletmeler için oluşturulan modellere başvurulabileceğini belirtilmiştir. TDSM' ye dayalı finansal verilerin kullanılmasıyla elde edilen Altman-Z skoru sonuçlarına göre halka açık olmayan işletmeler modeli, halka açık işletmelere göre $\% 0,01$ oranında daha yakın sonuçlara ulaşıldığı ve birbirlerine uyumun $\% 96,77$ olduğunu belirtmiştir.

Çelik (2018) Borsa İstanbul'da işlem görmekte olan imalat sektörü şirketlerinin finansal başarısızlık durumunu Altman Z-Skor yöntemi kullanarak gerçekleştirmiştir. Çalışmada 20152017 yılları arasında imalat sektöründe bulanan BISST-30 endeksindeki şirketler ele alınmıştır. Çalışma konusu şirketler arasında yer alan 2 firmanın araştırma konusu yıllar içerisinde eşik değerin altında olduğu, diğer firmaların ise eşik değerlerin üstünde skor elde ettikleri belirtilmiştir.

Büyükarıkan ve Büyükarıkan (2014) bilişim sektöründe Borsa İstanbul'da işlem gören şirketlerin 2008-2013 yılları arasında finansal başarısızlıklarını incelemek amacıyla Altman Z-Skor ve S-Skor modelleri kullanmışlardır. Her iki model benzer sonuçlar vermiştir. Şirketler arasında ANELT eşik değerlerin altında bir skor almıştır.

Özdemir ve diğerleri (2012) TDMS' ye göre raporlanmış finansal verilerin finansal başarısızlık modeli ile açıklanmasında DD esaslı modelin PD esaslı modele göre daha yüksek uygunluğa sahip olduğunu belirtmiştir. UFRS'e göre raporlanmış finansal verilerin finansal başarısızlık modellemelerinde PD esaslı modelin DD esaslı modele göre daha yüksek uygunlukta olduğu sonucuna varılmıştır.

Yıldız (2014) BİST 100 içerisinde işlem gören 35 şirket derecelendirmelerini ikili lojistik regresyon yöntemi ile Altman Z-Skor yöntemi iliş̧isini değerlendirmiştir. Sayısal veriler için Year 4/ 2020, Volume-4, Issue-2 | www.ispecjournal.org 
Altman Z-skor kullanılırken sayısal olmayan veriler için Kurumsal Yönetim Endeksi kullanılmış ve analiz sonucunda pozitif ilişki olduğu sonucuna ulaşılmıştır.

Altman ve diğerleri (2017) uluslararası alanda faaliyet gösteren Avrupa ve Avrupa dış1 şirketler üzerine finansal başarısızlık ölçümlemesini gerçekleştirmiş, mevcut Z-skor modelinin farklı ülke şirketleri, farklı istatistikler ve ek değişkenler ile yeni tahminleme yapabilmek amaciyla yedi araştırma hipotezi oluşturulmuştur. Tahmin verileri 31 ülkeden alınmıştır. Z-skorunun çoğu ülkede iyi çalıştığı, sınıflandırmanın doğru seçimi ve ek değişkenler ile ülkelere özgü daha da geliştirilebileceği öngörülmüştür.

\section{Veri ve Yöntem}

Çalışmanın amacı Borsa İstanbul'da işlem görmekte olan teknoloji alanındaki şirketlerin finansal başarısızlık ve buna bağlı iflas riskinin araştırılmasıdır. Literatürde önemli oranda kullanılmış olan Altman Z-Skor yöntemi ile BİST teknoloji şirketlerinin bulunduğu XUTEK endeksi içerisindeki 16 teknoloji şirketinin Aralık 2019 bilanço verileri üzerinden analiz gerçekleştirilmektedir. Şirket bilanço verileri için Kamu Aydınlatma Platformu (KAP), (www.isyatirim.com.tr, 2020), (www.fintables.com.tr, 2020) kullanılmıştır.

Altman (1968), 1946-1965 yılları arasında iflas dilekçesi veren ve finansal açıdan daha iyi durumda olan her grupta 33 imalat şirketin bulunduğu 2 grup belirlemiştir. Grup içerisinde şirketlerin aktif büyüklükleri 0,7 milyon ile 25,9 milyon USD arasında değişmektedir. Literatürdeki oran analizlerinden 22 rasyo arasından 5 temel rasyo seçilmiştir. Seçilen 5 temel rasyonun diskriminant fonksiyonu ile katsayılarının ağırlandırılmasının toplamından elde edilen Z-Skoru sonucuna ulaşılmaktadır (Miller, 2009).

$\underline{\mathbf{Z} \text { skor }}$ analizi sonucunda elde edilecek verilerin yorumlanmasına esas teşkil eden gruplandırma şöyledir:

$Z>$ 2,99 - işletmenin kredi geri ödemesinde tehlike bulunmamaktadır,

$Z<1,81$ - temerrüt tehlikesi vardır,

$1,81<Z<2,99$ - işletmeyle ilgili daha fazla inceleme gereksinimi bulunmaktadır,

$Z=2,675$ ise tehlikesiz işletmelerin başarısız işletmelerden ayrıldığı sınırdır (Moriarty, 1979).

$\mathrm{Z}=0.012 \mathrm{X} 1+0.014 \mathrm{X} 2+0.033 \mathrm{X} 3+0.006 \mathrm{X} 4+0.999 \mathrm{X} 5$ (halk açık imalat işletmeleri için)

Formülde yer alan $\mathrm{X}$ değerlerinin ifade ettiği rasyolar şöyledir: 
X1= Net İşletme Sermayesi / Aktif Toplamı

X2= Dağıtılmayan Kar / Aktif Toplamı

X3= Faiz ve Vergi Öncesi Kar / Aktif Toplamı

X4= Özkaynakların Piyasa Değeri / Toplam Yükümlülükler

X5 = Net Satışlar / Aktif Toplamı

Yukarıdaki eşitliğin kullanılması ile elde edilen Z-Skorun değerlendirilmesi ile ilgili olarak aşağıdaki referans aralıkları belirlenmiştir:

$\mathrm{Z}>2.99$ ise finansal başarılı,

$1.8<\mathrm{Z}<2.99$ ise gri bölge,

$\mathrm{Z}<1.8$ ise finansal başarısız.

Altman-Z skoru halka açık imalat sektörü üzerinde yaptığı çalışmada kullandığı ilk modelinde yer alan rasyoların açıklamaları şu şekildedir:

X1-Net İşletme Sermayesi / Aktif Toplamı: Kurumsal problemlerle ilgili çalışmalarda sıklıkla bulunan Çalışma sermayesi / Toplam aktifler oranı, toplam aktifleştirmeye göre net likit varlıklarının bir ölçüsüdür. Döner sermaye, dönen varlıklar ile kısa vadeli borçlar arasındaki fark olarak tanımlanır. Likidite ve büyüklük özellikleri dikkate alınmıştır.

X2-Dağıtılmayan Kar / Aktif Toplamı: Zaman içindeki birikimli kârlılık bu rasyoda dikkate alınmaktadır.

X3-Faiz ve Vergi Öncesi Kar / Aktif Toplamı: Bu oran, işletmenin faaliyet karından finansman giderlerinin çıkarılması ile elde edilir. Esasen, herhangi bir vergi veya kaldıraç faktöründen soyutlanarak, firma varlıklarının gerçek verimliliğinin bir ölçüsüdür. Bir firmanın nihai varlığı varlıklarının kazanç gücüne dayandığından, bu oran özellikle kurumsal başarısızlıkla ilgili çalışmalar için uygun görünmektedir.

X4-Özkaynakların Piyasa Değeri / Toplam Yükümlülükkler: Halka açık işletmelerde piyasa değeri hisse fiyatının ödenmiş sermayenin itibari hisse sayısı ile çarpılması sonucu bulunur. Toplam yükümlülük ise kısa ve uzun vadeli yükümlülüklerin toplamıdır.

X5-Net Satışlar / Aktif Toplamı: Sermaye-devir oranı standart bir firma varlıklarının satış yaratma kabiliyetini gösteren orandır. Yönetimin rekabetçi koşullarla başa çıkma kabiliyetinin bir ölçüsüdür. 
Altman halka açık imalat şirketlerinin finansal başarısızlık riskini bir yıl önceden \%90, iki yıl öncesinde ise \%82 oranında doğru tahmin etmektedir.

Model, özel endüstri ve imalat dışı işletmeler için güncellenerek iki farklı model daha ortaya çıkarılmıştır. Bu modeller Z' özel endüstri işletmeleri için, Z" modeli ise özel imalatçı olmayan şirketler için geliştirilmiştir (Altman, 2000; Aktaran Yıldız, 2014, s.77).

Z' Skor $=0.717 \mathrm{X} 1+0.847 \mathrm{X} 2+3.107 \mathrm{X} 3+0.42 \mathrm{X} 4+0.998 \mathrm{X} 5$ (özel endüstri işletmeleri için)

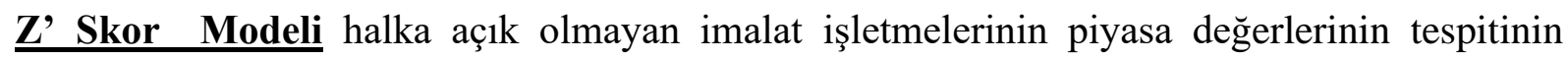
zorluğundan yola çıkarak X4 rasyosunu Özkaynakların Defter Değeri / Toplam Yükümlülükler olarak değiştirerek, piyasa değeri yerine defter değeri kalemini kullanılmıştır. Yapılan değişiklik ile halka açık olmayan imalat işletmelerin piyasa değerlerinin tespiti konusunun oluşturacağı sorunları modele özkaynakların defter değerini koyarak değiştirilmiştir. Z' modeli aşağıdaki gibidir (Aksoy ve Göker, 2018, s. 422-423):

Özkaynakların defter değeri şirketlerin mali tablolarındaki özkaynakların toplamını ifade eder. Özel imtiyazlı payların olmadığı şirketlerde şirket özsermayesi hisse sayısına bölünerek bulunur.

X1= Net İşletme Sermayesi / Aktif Toplamı

X2= Dağıtılmayan Kar / Aktif Toplamı

X3= Faiz ve Vergi Öncesi Kar / Aktif Toplamı

X4= Özkaynakların Defter Değeri / Toplam Yükümlülükler

X5 $=$ Net Satışlar / Aktif Toplamı

Halka açık olmayan firmalar için oluşturulan model ile elde edilen Z' skor aralıkları;

Z'> 2.90 ise finansal başarılı,

$1.23<Z^{\prime}<2.90$ ise gri bölge,

$Z^{\prime}<1.23$ ise finansal başarısız

olarak ifade edilmektedir.

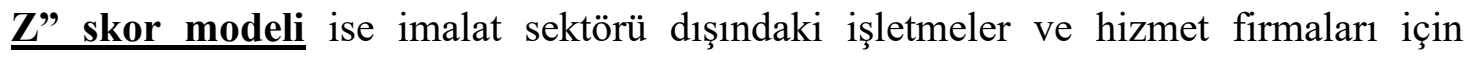
oluşturulmuştur. Z" skor modelinde halka açık olmayan imalat sektörü firmalarında olduğu 
gibi X4 değişkeninde özkaynakların defter değerini kullanmakta, X5 değişkenini ise tamamen ortadan kaldırmaktadır.

Z" Skor $=6.56 \mathrm{X} 1+3.26 \mathrm{X} 2+6.72 \mathrm{X} 3+1.05 \mathrm{X} 4$ (özel imalat işletmesi olmayan ve hizmet işletmeleri için)

Yeni elde edilen model için Z skor aralıkları ise;

Z"' $>2.6$ ise finansal başarıll,

$1.1<\mathrm{Z}$ " $<2.6$ ise gri bölge,

Z' $<1.1$ ise finansal başarısız

olarak güncellenmiştir.

X1= Net İşletme Sermayesi / Aktif Toplamı

X2= Dağıtılmayan Kar / Aktif Toplamı

X3= Faiz ve Vergi Öncesi Kar / Aktif Toplamı

X4= Özkaynakların Defter Değeri / Toplam Yükümlülükler

Modeller arasında Z" modelinde X5 değişkeni çıkarılmış ve endüstrinin potansiyel etkisinin minimize edilmesi amaçlanmıştır. Yapılan bu değişiklikler ile işletmelerin tür değişikliklerinden dolayı gerçekleşecek etkinin kaldırılmasını sağlayarak kredi risk değişimlerinin ölçülmesi amaçlanmıştır (Zhang ve Ellinger, 2006; Aktaran Yıldız, 2014, s.77).

Tablo 1: Altman Z Skor Modelleri'nin Skor Aralıklarının Karşılaştırması

\begin{tabular}{|c|c|c|}
\hline $\begin{array}{c}\text { Z skor :Halka Açık Imalat } \\
\text { Işletmeleri }\end{array}$ & Z' Özel Endüstri Işletmeleri & $\begin{array}{c}\text { Z" İmalatçı Olmayan ve Hizmet } \\
\text { sektörüi }\end{array}$ \\
\hline $\begin{array}{c}\text { Z skor > 2,99 } \\
\text { güvenli bölge (yeşil) }\end{array}$ & $\begin{array}{c}\text { Z skor }>2,90 \\
\text { (yeşil) güvenli kısım }\end{array}$ & $\begin{array}{c}\text { Z skor > 2,60 } \\
\text { (yeşil) güvenli kısım }\end{array}$ \\
\hline $\begin{array}{c}1,81<\mathrm{Z} \text { skor }<2,99 \\
\text { belirsiz }(\text { Gri })\end{array}$ & $\begin{array}{c}1,23<\text { Z skor }<2,99 \\
\text { Belirsiz }(\text { Gri })\end{array}$ & $\begin{array}{c}1,1<\text { Z skor }<2,60 \\
\text { Belirsiz (Gri) }\end{array}$ \\
\hline $\begin{array}{c}\text { Z skor < 1,8 } \\
\text { İflas riski (kırmızı) }\end{array}$ & $\begin{array}{c}\text { Z skor }<1,23 \\
\text { Iflas riski (k1rmız1) }\end{array}$ & $\begin{array}{c}\text { Z skor < 1,1 } \\
\text { İflas riski (kırmızi) }\end{array}$ \\
\hline
\end{tabular}

Kaynak: Yıldı, 2014, s.77.

Teknoloji firmalarında hizmet ve ürün üretiminin karma olması, imalat sektörlerinin maliyet ve satış oranlarından farklı bir iş sürecine yol açmaktadır. Bu çerçevede Z Skor modellerinden imalat dışı ve hizmet sektörü için kullanılan model tercih edilmiştir.

Year 4/ 2020, Volume-4, Issue-2 | www.ispecjournal.org 


\section{Bulgular}

Türkiye'nin 2018 y1lı içerisinde girmiş olduğu finansal kriz, tüm sektörleri etkilediği gibi kırılgan sektörlerde daha sert etkilere yol açmış olup, bu etki devam etmektedir. Mevcut çalışmada imalat sektörü dışındaki işletmeler ve hizmet işletmeleri için oluşturan model kullanılacaktır. Çalışma kapsamındaki BİST XUTEK endeksi şirketlerinin Altman Z-Skor yöntemi ile analizi için şirket bilanço verileri Kamu Aydınlatma Platformu (KAP), (www.isyatirim.com.tr, 2020) ve (www.fintables.com.tr, 2020) ile sağlanmıştır.

Z-skor analiz sonuçları anlamlandırması ise; Z" $>2.6$ ise finansal başarılı, $1.1<Z$ " $<2.6$ ise gri bölge, $Z$ " $<1.1$ ise finansal başarısız olarak değerlendirilecektir. Z-skor analizi için ilk adım olarak XUTEK endeksi şirketleri Aralık 2019 bilanço verileri ile Tablo 2'de yer alan rasyolar oluşturulmuştur.

Tablo 2: XUTEK Endeks Şirketleri Rasyoları

\begin{tabular}{|c|c|c|c|c|}
\hline Firma İsimleri & $\begin{array}{c}\text { Çalışma } \\
\text { Sermayesi/Toplam } \\
\text { Aktif }\end{array}$ & $\begin{array}{c}\text { Dağıtılmamış } \\
\text { Kar/Toplam Aktif }\end{array}$ & $\begin{array}{c}\text { Vergi ve Faiz } \\
\text { Ödemeleri Öncesi } \\
\text { Kârlar / Toplam } \\
\text { Aktifler }\end{array}$ & $\begin{array}{c}\text { Özkaynağın Defter } \\
\text { Değeri / Toplam } \\
\text { Yükümlülükler }\end{array}$ \\
\hline Escom & 0,298023539 & $\mathbf{X} 2$ & $-0,013994553$ & 22,99874013 \\
\hline Link & 0,685046447 & 0,39640993 & 0,171802839 & 6,07494274 \\
\hline Kfein & 0,355714286 & 0,097699197 & 0,198580286 & 4,713401324 \\
\hline Fonet & 0,037090674 & 0,142398791 & 0,227368169 & 5,392285856 \\
\hline Kront & 0,265249054 & 0,338903742 & 0,154864837 & 2,041819547 \\
\hline Netas & 0,74528562 & 0,120969971 & 0,014564445 & 0,364772954 \\
\hline Despc & 0,503134345 & 0,191547486 & 0,09653495 & 1,064897716 \\
\hline Pkart & 0,417350415 & 0,196417599 & 0,107459619 & 1,310783607 \\
\hline Dgate & 0,421509111 & 0,198706913 & 0,079687681 & 0,825469191 \\
\hline Logo & 0,172551165 & 0,294493812 & 0,183393704 & 1,035341472 \\
\hline Alctl & 0,456720247 & 0,109623941 & 0,046877569 & 0,581643727 \\
\hline Karel & 0,30008001 & 0,189079384 & 0,16603795 & 0,515667069 \\
\hline Asels & 0,24286395 & 0,183433274 & 0,111333251 & 1,124333724 \\
\hline Arena & 0,355228494 & 0,069166517 & 0,068828645 & 0,594784674 \\
\hline Armda & 0,326461388 & 0,046195555 & 0,040544769 & 0,328319494 \\
\hline Indes & 0,18308575 & 0,105316996 & 0,068928733 & 0,275919838 \\
\hline
\end{tabular}

Çalışma için kullanılan model, imalat sektörü dışındaki işletmeler için net çalışma sermayesi ve FAVÖK (Faiz ve Vergi Öncesi Kar) değerlerini daha ön plana çıkarmaktadır. Diğer bir ifade ile bu model, daha düşük borç, güçlü özsermaye yapısı ve vergi ve faiz ödemeleri öncesi kar oranının yüksek olan şirketleri ön plana çıkartmaktadır. 
Çalışma için oluşturulan rasyo değerleri kullanılarak Z-skor modeli ile finansal skor değerleri elde edilmiştir. Aşağıda yer alan model kullanılarak:

$\mathrm{Z} \mathrm{Skor}=6.56 \mathrm{X} 1+3.26 \mathrm{X} 2+6.72 \mathrm{X} 3+1.05 \mathrm{X} 4$

ile Z skoruna ulaşılmıştır. Z-skor sonuçları aşağıdaki tabloda verilmiştir.

Tablo 3: XUTEK endeksi şirketlerinin Altman Z-skorları

\begin{tabular}{|c|c|c|c|c|c|}
\hline $\begin{array}{l}\text { Firma } \\
\text { İsimleri }\end{array}$ & $\begin{array}{c}\text { Net İşletme } \\
\text { Sermayesi/ Aktif } \\
\text { Toplamı }\end{array}$ & $\begin{array}{l}\text { Dağıtılmayan } \\
\text { Kar/ Aktif } \\
\text { Toplamı }\end{array}$ & $\begin{array}{l}\text { Vergi ve Faiz Öncesi } \\
\text { Kâr / Aktif Toplam }\end{array}$ & $\begin{array}{l}\text { Özkaynakların } \\
\text { Defter Değeri / } \\
\text { Toplam } \\
\text { Yükümlülükler }\end{array}$ & Z-Skor \\
\hline & $X 1$ & $X 2$ & $X 3$ & $X 4$ & \\
\hline Escom & 1,9550344 & 0,9351627 & $-0,0940434$ & 24,148677 & 26,944831 \\
\hline Lınk & 4,4939047 & 1,2922964 & 1,15451508 & 6,3786899 & 13,319406 \\
\hline Kfein & 2,3334857 & 0,3184994 & 1,33445952 & 4,9490714 & 8,935516 \\
\hline Fonet & 0,2433148 & 0,4642201 & 1,52791409 & 5,6619001 & 7,8973491 \\
\hline Kront & 1,7400338 & 1,1048262 & 1,0406917 & 2,1439105 & 6,0294622 \\
\hline Netas & 4,8890737 & 0,3943621 & 0,09787307 & 0,3830116 & 5,7643204 \\
\hline Despc & 3,3005613 & 0,6244448 & 0,64871486 & 1,1181426 & 5,6918636 \\
\hline Pkart & 2,7378187 & 0,6403214 & 0,72212864 & 1,3763228 & 5,4765915 \\
\hline Dgate & 2,7650998 & 0,6477845 & 0,53550121 & 0,8667427 & 4,8151282 \\
\hline Logo & 1,1319356 & 0,9600498 & 1,23240569 & 1,0871085 & 4,4114997 \\
\hline Alctl & 2,9960848 & 0,357374 & 0,31501726 & 0,6107259 & 4,279202 \\
\hline Karel & 1,9685249 & 0,6163988 & 1,11577503 & 0,5414504 & 4,2421491 \\
\hline Asels & 1,5931875 & 0,5979925 & 0,74815944 & 1,1805504 & 4,1198898 \\
\hline Arena & 2,3302989 & 0,2254828 & 0,46252849 & 0,6245239 & 3,6428342 \\
\hline Armda & 2,1415867 & 0,1505975 & 0,27246085 & 0,3447355 & 2,9093805 \\
\hline Indes & 1,2010425 & 0,3433334 & 0,46320108 & 0,2897158 & 2,2972928 \\
\hline
\end{tabular}

Tablo 3'de analiz kapsamındaki firmaların Z skor değerleri yer almakta olup, yapılan hesaplamalara göre Escom firmasının elde ettiği Z-skoru sonucu ile ön plana çıktığ1 görülmektedir. Escom firmasının faaliyet raporu incelendiğinde, firmanın teknoloji alanında üretim süreçlerinin minimum olduğu, firmanın daha yoğun olarak teknoloji ve enerji piyasalarına yatırım yaptığı anlaşılmaktadır. Faaliyet raporunda belirtilen yeni iş süreç modeli firmanın bilançosunda fiilen üretim yapmadığı için üretim maliyeti, yükümlülükleri gibi kalemlerinin düşük olmasına yol açmıştır. Çalışma için uygulanan model içinde rasyoların düşük maliyet ve düşük yükümlülüklerin skorlara pozitif yansıması nedeniyle söz konusu 
firmanın yüksek puan almasını sağlamıştır. Yeni ekonomik modelinden dolayı Escom firmasının diğer firmalardan farklı tutulması gerektiği düşünülmektedir.

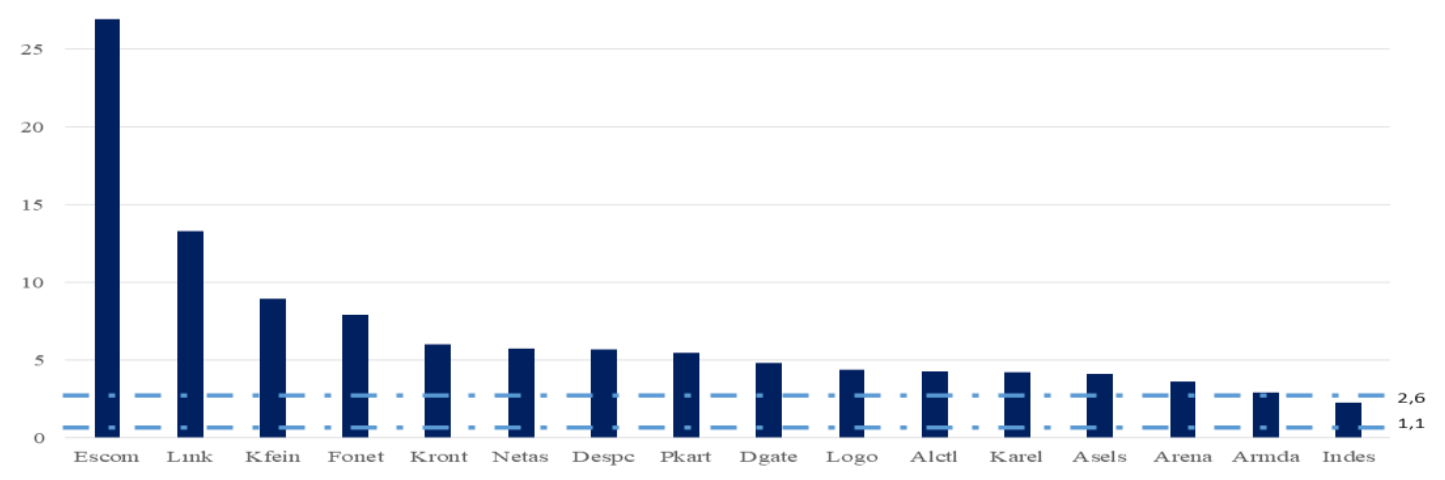

Grafik 3: Şirketlerin Z-Skor Sonuçları

Tablo 3 ve Grafik 3 incelendiğinde teknoloji firmalarının finansal başarılı skoru olan 2,6 değerinin üstünde bir ortalama gösterdikleri anlaşılmıştır. Firmalar arasında sadece İndes firması 2,29 puan ile gri bölgede kalmaktadır. Finansal başarısızlık eşik değeri olan 1,1 puan altında firma bulunmamaktadır. İndes firmasının 2019 bilançosu incelendiğinde hem ticari alacaklar kaleminin hem de kısa vadeli yükümlülüklerinin çok yüksek olduğu görülmektedir. Ticari alacakların nakit akışına dönüşümü ile kısa vadeli borçların azalmasının sağlanması durumunun İndes firmasına etkisi olumlu bir seyir olacaktır.

Çalışma konusu işletmelerin 2019 yılı BİST performansı için 2019 yılı başlangıç değeri ile 2019 yll sonu verileri değerlendirilmiştir. Tablo 4'de görüleceği üzere şirketlerin 2019 BİST değer değişimi, Türkiye'nin dönem içinde yaşadığı ekonomik dalgalanmalar ile beraber teknoloji firmalarının ne kadar keskin değer dönüşümleri yaşadığını göstermektedir.

Tablo 4: Şirketlerin Hisse Değer Değişimleri

\begin{tabular}{|c|c|c|c|}
\hline & $\begin{array}{c}\text { 2019 Başlangıç BíST Hisse } \\
\text { Verileri }\end{array}$ & $\begin{array}{c}\text { 2019 Yılsonu BİST } \\
\text { Hisse Verileri }\end{array}$ & \% Değişim \\
\hline Fonet & 1,47 & 7,69 & 523,13 \\
\hline Karel & 4,10 & 14,53 & 354,39 \\
\hline Pkart & 3,08 & 9,27 & 300,97 \\
\hline Logo & 26,42 & 60,80 & 230,13 \\
\hline Link & 8,20 & 18,15 & 221,34 \\
\hline Alctl & 5,61 & 12,04 & 214,62 \\
\hline Netas & 6,38 & 13,06 & 204,70 \\
\hline Dgate & 4,12 & 7,81 & 189,56 \\
\hline İndes & 5,34 & 9,70 & 181,65 \\
\hline Escom & 0,77 & 1,39 & 180,52 \\
\hline Arena & 4,05 & 7,29 & 180,00 \\
\hline Armda & 9,14 & 16,39 & 179,32 \\
\hline Despc & 2,61 & 4,24 & 162,45 \\
\hline Kront & 8,48 & 12,72 & 150,00 \\
\hline
\end{tabular}

Year 4/ 2020, Volume-4, Issue-2 | wWw.ispecjournal.org 


\begin{tabular}{|c|c|c|c|} 
Kfein & 11,81 & 13,70 & 116,00 \\
\hline Asels & 23,31 & 20,94 & 89,83 \\
\hline
\end{tabular}

Kaynak: www.isyatirim.com.tr

Aşağıdaki grafikte analiz kapsamındaki şirketlerin hisse değer değişimleri yer almaktadır.

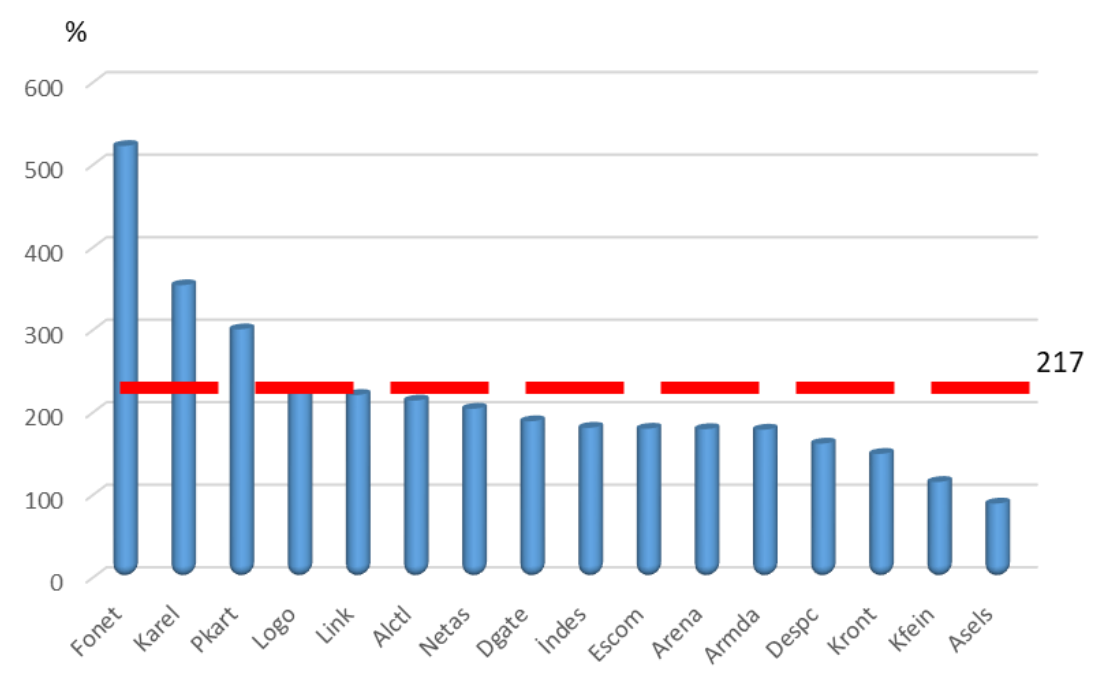

Grafik 4: Şirketlerin 2019 Hisse Değer Değişimi

Kaynak: www.isyatirim.com.tr

Çalışma konusu BİST XUTEK endeksi şirketlerinin Altman Z-skoru değerlerinin yüksek çıkması, finansal olarak pozitif bir görünüm çizdiklerini göstermektedir. Şirketlerin BİST 2019 yıl başı ve yıl sonu hisse verileri değerlendirildiğinde de finansal olarak pozitif görünümünün hisse değerlerine yansıdığg görülmektedir.

\section{Sonuç}

Stratejik sektörler arasında bulunan teknoloji firmaları finansal yapı ve pazar performansı bakımında diğer sektörler gibi piyasalarda yaşanan dalgalanmalardan etkilenmektedir. Türkiye'de yaşanan 2018 finansal krizinin etkilerinin uzun dönemde de etkisinin devam edeceği ifade edilebilir. Nitekim, BİST XUTEK endeksinde işlem gören şirketler üzerine yapılan mevcut çalışmada finansal krizin etkileri görülmektedir.

BİST XUTEK endeksi çalışmanın yapıldığı 2019 yılı için başlangıç değeri 92,885.33 iken yı1 içerisinde, en büyük değeri 22 Şubat 2019 tarihinde 104,753.03, en düşük değeri 23 Mayıs 2019'da 71,408.11, yıl sonu ise 30 Aralık 2019 tarihinde 100.301,24 değerleri görülmüştür (https://www.isyatirim.com.tr/). XUTEK endeksinin 2019 yılındaki değer değişimleri 
sektörün kırılganlığını ortaya koymaktadır. Yüksek volatiliteye sahip bir sektör içerisinde yer alan teknoloji şirketlerinin, finansal risk uyarı sistemlerini güçlü tutmaları gerekmektedir. Aksi halde yüksek volatilite her zaman finansal başarısızlık, iflas riski gibi istenmeyen durumlarla sonuçlanabilir.

Türkiye'de gerçekleşen finansal krizlerde ilk etkilenen firmalar düşük çalışma sermayesi, yüksek borçlanmanın yanı sıra özellikle kısa vadeli borçlanma araçlarının çalışma sermayesi yerine kullanılması ve düşük FAVÖK oranlarıyla çalışmayı tercih edenler olarak ön plana çıkmaktadır. Çalışma için kullanılan Altman Z-skorun imalat dışı sektörler için güncellenen modelinin rasyo ve katsayıları, sektör firmalarının faaliyetlerinin sürdürülebilir ve karlı bir iş süreci oluşturmalarını, aksi halde finansal başarısızlık ve iflas riskinin yüksek olacağını göstermektedir.

Çalışma XUTEK endeksinde işlem görmekte olan teknoloji firmalarının yüksek Z-skorları elde ettikleri, bunun gerekçesi olarak da özellikle yüksek çalı̧̧ma sermayesi ve FAVÖK oranlarına sahip olmalarının etkili olduğu ifade edilebilir. Teknoloji, sektör olarak AR-GE ve başlangıç yatırımlarına yoğun olarak ihtiyaç duymaktadır. Sektörün çok hızlı dönüşümler geçirmesi ve büyüme hızlarının diğer sektörlere göre çok farklı olması, iş süreçlerinin değişken ve yaratıcılığın ön planda olması, yatırımcılar açısından da sektör şirketlerine karşı risk iştahının yüksek olması ile beraber bilinmezlik de yaratmaktadır.

Z-skor değeri incelendiğinde İndes dışındaki firmaların 2,6 skorunun üzerindeki finansal başarılı olarak eşik değerinin üstünde puanlara ulaştı̆ı görülmektedir. Şirketlere ait rasyolara bakıldığında Escom firmasının iş modelini değiştirmesinin sonucu olarak Z-skor değerinin diğer firmalara göre yüksek çıktığı sonucuna ulaşılmıştır. Modelin rasyoları incelendiğinde en yüksek Z-skorlarında; Link, Kfein, Fonet, Kront gibi firmaların ön plana çıktığı saptanmıştır. Ayrıca modelin rasyo bölümleri ayrı ayrı incelendiğinde;

- Çalı̧̧ma sermayesinde Link, Netas, Despc firmaları,

- FAVÖK değerleri bakımından; Link, Kfein, Fonet, Logo firmaları,

- Özkaynağın defter değeri/ toplam yükümlükler rasyosunda; Link, Fonet, Kront, Kfein firmaları ön plana çıkmaktadır. 
Altman Z-skoru ile elde edilen pozitif yönlü değerler, BİST 2019 yılı şirket hisse değerlerinde de görülmektedir. İki ölçünün pozitif yönlü olması, finansal sonuçların şirket değerlerine de yansıdığını kanıtlamaktadır.

Sektör şirketlerinin küreselleşen dünyada teknoloji bilişim sektörünün ne kadar hızlı geliştiği, BİST hisse değerlerindeki pozitif görünümlerindeki hızlı çıkışlarından da görülmektedir. Teknoloji şirketlerinin hızlı gelişimleri ve dünya üzerindeki teknolojik yaşam tarzının gelişmesi ile yüksek oranda büyüme gerçekleştirecekleri öngörülebilmektedir. Yüksek hareket ve değişim aktifliğine sahip olan sektör için finans yönetimi ve risk yönetim becerileri dönüşümlerinin daha hızlı ve büyüme potansiyellerinin daha yüksek olmasını sağlayacaktır. Yatırımcılar için şirketlerin finansal göstergelerinin güçlü olması, finansal kaynaklara daha düşük maliyet ve daha yüksek oranlarda ulaşabilmelerini sağlayacaktır.

\section{Kaynakça}

Aksoy Akın, E.E, Göker Kandil, İ.E. (2018). bankacılık sektöründe finansal risklerin z-skor ve bankometer metodları ile tespiti, Bist’te işlem gören ticari bankalar üzerine bir araştırma, Muhasebe Bilim Dünyası Dergisi, 20(2), 418-438.

Altman E. I. (2000). Predicting financial distress of companies, revisiting z-score and zeta models, http://pages.stern.nyu.edu/ ealtman/Zscores.pdf 09.04.2020.

Altman, E. (1968). Financial ratios, discriminant analysis and the prediction of corporate bankruptcy. The Journal of Finance, 23(4), 589-609.

Altman, E.I, Drozdowska, M.I, Laitinen, E.K, Suvas, A. (2017) Financial distress prediction in an international context: a review and empirical analysis of altman's z-score model, Journal of International Financial Management \& Accounting, 28(2).

Altman, E. I. ve Hotchkıss, E. (2006). Corporate financial distress and bankruptcy: predict and avoid bankruptcy, Anaylze and Invest in Distressed Debt. 3. bs. New Jersey : John Wiley and Sons.

Beaver, William H.(1966). Financial ratios as predictors of failure, in Empirical Research in Accounting, Selected Studies, in Supplement To The Journal Of Accounting Research, 71-111. Büyükarıkan, U. ve Büyükarıkan, B. (2014). Bilişim sektöründe faaliyet gösteren firmaların başarısızlık tahmin modelleriyle incelenmesi, Akademik Bakış Dergisi, 46, 160-172.

Çelik, M. S. (2018). Altman z-skor modeli kullanılarak Bist-30 endeksinde yer alan imalat şirketlerinin finansal başarısızlık riskinin tahmin edilmesi, 5. Uluslararası Politik, Ekonomik ve Sosyal Araştırmalar Kongresi (ICPESS), 26-29 Ekim 2018, 525-535. 
Fındık, D. ve Tiryakioğlu, M. (2017). Türkiye'de bilgi ve iletişim teknolojilerinin kullanımına yönelik politika ve öneriler, Ankara Üniversitesi SBF Dergisi, 72(3). 639-668.

Hayes, S.K., Hodge, K.A., Hughes, L.W. (2010). A study of the efficacy of altman's z to predict bankruptcy of specialty retail firms doing business in contemporary times, Economics \& Business Journal: Inquiries \& Perspectives, 3(1), 122-135.

Kulalı, İ. (2016). Altman z-skor modelinin Bist şirketlerinin finansal başarısızlık riskinin tahmin edilmesinde uygulanması, Uluslararası Yönetim İktisat ve İşletme Dergisi, 12(27). 283- 291

Mammadli, A. Helhel, Y. (2017). Fortune 100 listesinde yer alan turizm şirketleri için Altman $\mathrm{Z}$ skor, 1. Uluslararası Turizmin Geleceği Kongresi: Inovasyon, Girişimcilik ve Sürdürebilirlik Kongresi (Futourism 2017).

Miller, W. (2009). Comparing models of corporate bankruptcy prediction: Distance to default vs. Z-score. Morningstar, Inc.

Moriarty, S. (1979). Communicating financial information through multidimensional graphics, Journal of Accounting Research, 17(1), 205-224.

Orçun, Ç. Eren, B. S. (2017). TOPSIS yöntemi ile finansal performans değerlendirmesi: XUTEK üzerinde bir uygulama, Muhasebe ve Finansman Dergisi, Temmuz 2017 özel sayl.

Özdemir, F. S. (2014). halka açık ve halka açık olmayan işletmeler yönüyle tekdüzen muhasebe sistemi ve Altman z skor modellerinin uygulanabilirliği, Ege Akademik Bakış, 14(1), 147-16.

Özdemir, F. S., Choi, F., and Bayazıtlı, E. (2012). Finansal Başarısızlık Tahminleri Yönüyle UFRS ve Bilginin İhtiyaca Uygunluğu. Mali Çözüm Dergisi, 17-52.

Sulub, A.S. (2014). Testing the predictive power of Altman's revised Z' model: The case of 10 multinational companies, Research Journal of Finance and Accounting, 5(21), 174- 184.

Toker, K. Çınar, F. (2018). Türkiye'de Borsa İstanbul Teknoloji Endeksi (Xutek) ile ihracatın ithalatı karşılama oranı arasındaki ilişkinin incelenmesi, Beyder, 13(2), 139-150.

Zhang, T. And Ellinger, P. (2006). Credit risk and financial performance assessment of 1llınois farmers: a comparison of approaches with farm accounting data, American Agricultural Economics Association Annual Meeting, Long Beach California. 


\section{Internet kaynakları}

www.fintables.com.tr

www.isyatirim.com.tr

www.tubisad.org.tr 